Çukurova Üniversitesi Mühendislik Fakültesi Dergisi, 36(1), ss. 273-281, Mart 2021

Çukurova University Journal of the Faculty of Engineering, 36(1), pp. 273-281, March 2021

\title{
Asidik/Bazik Ortamlarda ve Farklı Miktarlarda Çapraz Bağlayıcı ile Elde Edilen Silika Kaplamaların Pamuklu Denim Kumaşlara Etkilerinin İncelenmesi
}

\author{
Sabiha SEZGİN BOZOK ${ }^{* 1}$, R. Tuğrul OĞULATA ${ }^{1}$ \\ ${ }^{l}$ Çukurova Üniversitesi, Mühendislik Fakültesi, Tekstil Mühendisliği Bölümü, Adana
}

Geliş tarihi: 15.02.2021 Kabul tarihi: 31.03.2021

Öz

Tekstil ürünlerinin özelliklerinin geliştirilebilmesi ve ürünlere yeni özellikler kazandırılabilmesi açısından fonksiyonel kaplama işlemleri üzerine birçok çalışma yapılmaktadır. Bu çalışmada da fonksiyonel bitim işlemleri arasında tekstil alanı için önemli bir yeri olan sol-jel tekniği ile günlük hayatta kullanımı en yaygın tekstil ürünlerinden birisi olan denim kumaşlara kaplama işlemi uygulanmıştır. Bu doğrultuda çapraz bağlayıcının farklı hacimsel oranlarda sol kompozisyonuna eklenmesinin ve başlatıcı maddelerin asidik ve bazik katalize edilmiş hidrolizin pamuklu denim kumaşlara etkisini incelemek amaçlanmıştır. Numunelerin SEM analizi görüntülerinde kaplama sonrası yüzey yapılarının değiştiği, sol oluşumu asidik ortamda gerçekleştiğinde ve sol bileşenlerinden çapraz bağlayıcı maddenin miktarı arttıkça numunelerin ağırlığının arttığı tespit edilmiştir. Numunelerin kaplama sonrası sertleştiği, hava geçirgenliklerinin arttığı ve bazı numunelerin aşınma dayanımlarının bir miktar arttığı görülmüştür.

Anahtar Kelimeler: Denim kumaş, Sol-jel işlemi, Sertlik, Hava geçirgenliği, Aşınma dayanımı

\section{Investigation of the Effects of Silica Coatings Obtained in Acidic/Basic Environments and with Different Amounts of Crosslinkers on Cotton Denim Fabrics}

\begin{abstract}
Many studies are carried out on functional coating processes in order to improve the properties of textile products and to gain new features. In this study, the coating process was applied to denim fabrics, which is one of the most common textile products used in daily life, with the sol-gel technique, which has an important place among the functional finishing processes for the textile field. Accordingly, it is aimed to examine the effect of adding crosslinker to sol composition in different volumetric proportions and catalyzed hydrolysis in acidic and alkaline environment of precursors on cotton denim fabrics. In the SEM analysis images of the samples, it was determined that the surface structures of the samples changed after coating, the weight of the samples increased when sol composition occurred in an acidic environment and the amount of crosslinker from the sol components increased. It was observed that the samples stiffened after coating, their air permeability increased and the abrasion resistance of some samples increased a little.
\end{abstract}

Keywords: Denim fabric, Sol-gel process, Stiffness, Air permeability, Abrasion strength

*Sorumlu yazar (Corresponding author): Sabiha SEZGIN BOZOK, sbozok@cu.edu.tr 


\section{GİRIŞ}

Denim, genel olarak sıkı yapısıyla bilinmekte olup çözgü ipliği indigo boyalı, atkı ipliği boyasız ve 3/1 Z dimi dokuma kumaş olarak üretilmektedir.

Günlük hayatta ve geniş yaș aralı̆̆ında kullanımı oldukça yaygın olan denim kumaşın piyasa değeri 2019 yılında 90 milyar ABD dolar olarak kaydedilmiştir ve bu rakamın 2023 yılına kadar 105 milyar dolara çıkması beklenmektedir [1].

Denim kumaşların temel üretim adımları sırasıyla; iplik eğirme, çözgü hazırlama, iplik boyama, haşıllama işlemi, dokuma, terbiye, kontrol ve katlama, paketleme ve sevkiyat şeklindedir [2].

Çoğu tekstil ürününde olduğu gibi denim kumaşlar içinde farklı bitim işlemi teknikleri uygulanmaktadır. Literatürde boyama özelliklerini geliştirmek ve farklı renk efektleri elde edebilmek, mekaniksel dayanımı, konfor özellikleri iyileştirmek, güç tutuşurluk, kendi kendine temizleyebilme gibi farklı özellikler kazandırmak amacıyla denim kumaşlarla ilgili farklı çalışmalar bulunmaktadır.

Hidrofilik poliüretan ile denim kumaş üzerine kaplama uygulayan Güneşoğlu (2015), bu işlem ile denim kumaşlara su iticilik özelliği kazandırıldığını, su buharı geçirgenliğinin düştüğünü, fazla miktarda poliüretan ile kaplanan denim kumaşların aşınma dayanımlarının iyileştirilmiş olduğunu tespit etmiştir [3].

Denim kumaşlara şardonlama ve laminasyon uygulayan Sabır ve Kadem (2016), bu işlemlerin kumaşların 1sıl dirençlerini iyileştirdiğini, şardonlama işleminin hava geçirgenliğini arttırdığını, laminasyon işleminin denim kumaşları sertleştirdiğini tespit etmişlerdir [4]. Uğur ve Sarışık (2015), denim kumaşların mekaniksel dayanımını arttırabilmek amacıyla kumaşlara $\mathrm{Al}_{2} \mathrm{O}_{3}$ nanopartikülleri çok katmanlı film biriktirme yöntemiyle uygulamışlardır. Sonuçlarda bu yöntem ile denim kumaşların atkı ve çözgü yönünde gerilme mukavemetlerinin arttırıldığını ve mekaniksel stabilitelerinin iyileştirilebildiğini tespit etmişlerdir [5].
Tek yüze bıçakla kaplama metodu uygulayarak denim kumaşlara kaplama işleme uygulayan Tölek ve Kadem (2016) kumaşların işlemler sonrası ağırlıklarının arttığını, zemin kumaş kalınlığının azaldığını ve kopma mukavemetinin arttığını, su buharı geçirgenliğinin azaldığını, kumaş sertliğinin arttığını, boncuklanma dayanımının arttığını tespit etmişlerdir [6].

Bu çalışmada da modern kaplama yöntemlerinden olan sol-jel tekniği uygulanarak denim kumaşlara kaplama işlemi uygulanmıştır.

Sol-jel tekniği inorganik ya da organik fonksiyonel kaplamalar elde edilebilen, etkili, çevre dostu bir kimyasal teknolojidir [7]. Sol, sıvı içerisindeki kolodyal katı partiküllerin stabil süspansiyonlarına, jel ise birbirine üç boyutlu şekilde bağlanmış katı ağlara denilmektedir [8].

İşlem, reaktif alkoksit grup içeren (-OR) metal alkoksit maddenin/maddelerin hidrolizasyonu ve kondenzasyon reaksiyonları ile başlamaktadır [9]. $\mathrm{Bu}$ başlatıcı maddeler ortamda katalizör olarak asit ya da baz minerali kullanıldığında su, etanol gibi çözücü içerisinde kolaylıkla reaksiyona girebilmektedirler. Katalizör olarak asit kullanıldığında ve pH 2-7 arasındayken partikül boyutları 2-4 nm aralığında olurken; baz kullanıldığında ve ortam pH 7'den yüksekken daha büyük parçacıklar elde edilebilmektedir [8]. Sol elde edildikten sonra malzemeyi kaplama işlemi gerçekleştirilir ve ardından kurutma ve kürleme işlemi yapılır [10].

Sol elde edilirken ya da edildikten sonra farklı katk1 maddeleri eklenerek kimyasal veya fiziksel modifikasyon yapılabilmektedir. Bu maddeler ile malzemenin renk haslıkları, mekaniksel dayanımları iyileştirilebilmekte, antibakteriyel, güç tutuşurluk, kendi kendini temizleyebilme, elektriksel iletkenlik gibi farklı fonksiyonel özellikler kazandırılabilmektedir [11].

Çalışma kapsamında herhangi bir katkı maddesi olmadan farklı oranlarda çapraz bağlayıcı içeren, düşük ve yüksek $\mathrm{pH}$ seviyelerinde ayrı ayrı elde edilen sol kompozisyonlarının denim kumaşlara etkisi incelenmiştir. 


\section{MATERYAL VE METOD}

\subsection{Materyal}

Deneysel çalışmada çözgü ipliği sentetik indigo boyalı (Open-end, $\mathrm{Ne} 8,25)$, atkı ipliği boyasız (Open-end, Ne 12), \%100 pamuk içerikli ticari denim kumaş kullanılmıştır. Kumaş 3/1 Z dimi dokunmuş, atkı sıklığı 16 iplik/cm; çözgü sıklığ1 $25 \mathrm{iplik} / \mathrm{cm}$ olup gramaj1 $277,4 \mathrm{gr} / \mathrm{m}^{2}$ ' dir. Kumaşın üretim sonrası haşılı sökülmüş ve bitim işlemine hazır hale getirilmiştir.

Sol-jel tekniği ile bitim işlemi uygulamak için kullanılan kimyasallar TEOS (Tetraetilortosilikat, $\geq \% 99$, Sigma-Aldrich), GPTS ((3glisidiloksipropil) trimetoksisilan, \%98, Sigma Aldrich), $\mathrm{HCl}$ (Hidroklorik asit, \%37, Sigma Aldrich), $\mathrm{NaOH}$ (Sodyum hidroksit, $\geq \% 97$, Tekkim), etanol (\%96, Tekkim) şeklindedir.

\subsection{Metod}

Sol-jel tekniği kullanılarak çalışmada altı farklı numune elde edilmiştir. Değişken parametrelerden birisi TEOS ve çapraz bağlayıcı olan GPTS'nin farklı hacimsel oranları, diğeri ise hidroliz katalizör olarak $\mathrm{HCl}$ veya $\mathrm{NaOH}$ eklenerek farklı pH seviyelerinde sol elde edilmesi şeklinde belirlenmiştir. İşlem görmemiş numuneler değerlendirmeler için "Referans" olarak adlandırılmıştır. İşlem gören numunelerin kodları ve uygulanan işlem özellikleri Çizelge 1'de sunulmuştur [12,13].

Sol elde edilebilmesi için ilk adımda TEOS ve istenilen duruma göre GPTS bir beher içine başlatıcı madde olarak koyulmuştur. Ardından behere bir miktar distile su ve etanol ilave edilmiştir. $24 \pm 2{ }^{\circ} \mathrm{C}$ 'de sürekli karıştırılan çözeltiye asidik veya bazik karışımlar elde edilmek üzere $0,01 \mathrm{M} \mathrm{HCl}$ veya $0,1 \mathrm{M} \mathrm{NaOH}$ eklenmiştir. Karışım saydam hale gelince karıştırma işlemine son verilmiştir.

Hazırlanan karışımlar küçük bir tekne içerisine alınmıştır. Belirli boyutlarda kesilen denim numuneler tek tek bu teknelerdeki solüsyonlara 60 sn süre boyunca daldırılmıştır. Ardından \%85 pick-up ile laboratuvar tipi fulard makinesinden geçirilmiştir. Islak numuneler bekletilmeden $85^{\circ} \mathrm{C}$ 'de etüv içerisinde kurutulmuş ve ardından $120{ }^{\circ} \mathrm{C}$ 'de 120 saniye boyunca fikse işlemine tabii tutulmuştur. Tüm bu işlemler iki kez tekrarlı olarak gerçekleştirilmiştir.

Çizelge 1. Numune kodları ve işlem özellikleri

\begin{tabular}{|c|c|c|c|}
\hline Numune & $\begin{array}{c}\text { TEOS ve GPTS } \\
\text { hacimsel oran } \\
\text { (TEOS:GPTS) }\end{array}$ & $\begin{array}{c}\text { Ortam } \\
\text { şart1 }\end{array}$ & $\mathrm{pH}$ \\
\hline D1 & $11: 0$ & Bazik & $9-9,5$ \\
\hline D2 & $11: 0$ & Asidik & $3-3,5$ \\
\hline D3 & $11: 4$ & Bazik & $9-9,5$ \\
\hline D4 & $11: 4$ & Asidik & $3-3,5$ \\
\hline D5 & $11: 8$ & Bazik & $9-9,5$ \\
\hline D6 & $11: 8$ & Asidik & $3-3,5$ \\
\hline
\end{tabular}

Uygulanan kimyasal işlemin lif yüzeyindeki etkisini görebilmek için FEI Quanta 650 Field Emission marka SEM (Scanning Electonic Microscope) analizi ile işlem görmüş ve görmemiş tüm numunelerin x5000 büyütme ile görüntüleri elde edilmiştir. Tüm kimyasal işlemlerin numunelerin kütle değişimine etkisini tespit edebilmek için aşağıdaki Eşitlik 1 kullanılmıştır. $\mathrm{Bu}$ eşitlikte " $\mathrm{M}_{1}$ " numunenin işlem sonrası ağırlığını, " $\mathrm{M}_{2}$ " numunenin işlem öncesi ağırlığını temsil etmektedir.

Küte Değişimi $(\%)=\left(\mathrm{M}_{1}-\mathrm{M}_{2}\right) / \mathrm{M}_{1}$

Farklı hacimsel oranlardaki TEOS ve GPTS'nin ve farklı $\mathrm{pH}$ seviyelerinin kaplanan denim numunelere etkisini incelemek için sertlik tayini, hava geçirgenliği ve aşınma dayanımı tayini analizleri uygulanmıştır. Gerçekleştirilmiş testlerin standart ve diğer analiz bilgileri Çizelge 2'de sunulmuştur [14-16]. 
Asidik/Bazik Ortamlarda ve Farklı Miktarlarda Çapraz Bağlayıcı ile Elde Edilen Silika Kaplamaların Pamuklu Denim Kumaşlara Etkilerinin İncelenmesi

Çizelge 2. Numunelere uygulanan testler, standartları ve analiz detayları

\begin{tabular}{|l|l|l|l|}
\hline Test adı & Standart & Cihaz & Analiz detayları \\
\hline Sertlik & ASTM D 4032-94 & A\&T Stiffness & $\begin{array}{l}\text { Dairesel eğilme metodu, 3 bar } \\
\text { basinçta }\end{array}$ \\
\hline Hava geçirgenliği & ISO 9237:1995 & Prowhite EP08M & $\begin{array}{l}10 \mathrm{dm}^{3} \text { hava basınc1, 20 } \mathrm{cm}^{2} \text { numune } \\
\text { test alanı }\end{array}$ \\
\hline Aşınma dayanımı & ISO 12947-3 & $\begin{array}{l}\text { James Heal- } \\
\text { Martin Dale }\end{array}$ & $\begin{array}{l}\text { Kütle kayb1 metoduna göre, 15000 } \\
\text { devir, 9 kPa ağırlık }\end{array}$ \\
\hline
\end{tabular}

\section{BULGULAR VE TARTISYMA}

\subsection{SEM Analizi}

İşlem görmüş ve işlem görmemiş referans numunenin x5000 büyütme ile elde edilmiş görüntüleri Şekil 1'de verilmiştir. Görüntüler incelendiğinde işlem görmüş tüm numunelerin lif yüzey yapılarının değişmiş olduğu görülmektedir. Referans numunenin lif yüzeyi düzgünken işlem görmüş numunelerin lif yüzeyindeki kserojel yapının homojen olmadığı görülmüştür. Uygulanan kaplamanın lif yüzeyini pürüzlü hale getirdiği, yüzeyin bazı kısımlarının dalgalı bir görünüme sahip olduğu tespit edilmiştir.

Sol oluşumunda değişen hacimsel oranlarda TEOS ve GPTS'nin ve farklı $\mathrm{pH}$ seviyelerinin kserojel yapının görünümünde anlamlı bir etkiye sahip olmadığı görülmektedir. Üst üste yerleşmiş görünen kaplamanın denim numunelerin lif çapını kalınlaştırdığı düşünülmektedir.

\subsection{Numunelerin İşlemler Sonrası Kütle Değişimleri}

Şekil 2'de kaplama işlemleri sonrası numunelerin ilk ağırlığına göre yüzde (\%) olarak kütle değişimleri görülmektedir. Sol-jel tekniği ile uygulanan kaplama işlemi tüm denim numunelerde kütle artışına sebep olmuştur.

Sol oluşumununda asidik ve bazik ortamların numunelerin kütle değişimine etkisi açısından kıyaslandığında; D2>D1, D4>D3, D6>D5 şeklinde bir sonuç alınmıştır. $\mathrm{Bu}$ sonuç asidik ortamda meydana gelen silika solün selüloz içerikli numuneye daha fazla miktarda bağlandığını göstermiştir.

Sol kompozisyonundaki TEOS ve GPTS hacimsel oranların kütle değişim yüzdelerine etkisi incelendiğinde ortalama olarak en fazla kütle artışının D5 ve D6 numunelerinde olduğu, yani TEOS:GPTS 11:8 hacimsel oranda kaplama ile numune arasındaki bağın diğer oranlardaki sollere göre daha yüksek olduğu sonucuna varılmıştır. Bu durum çapraz bağlayıcı maddenin (GPTS) malzeme yüzeyi ile silika sol kaplama arasındaki adhezyon kuvvetini arttırdı ğ 1 bilgisini desteklemektedir [10].

\subsection{Sertlik Tayini}

Şekil 3'de işlem görmüş ve işlem görmemiş referans denim numunelerin ' $\mathrm{kg}$ ' cinsinden sertlik değerleri sunulmuştur. Sol-jel tekniği ile uygulanan tüm işlemler denim numunelerin sertliğini arttırmıştır. İnorganik madde içeren kaplamaların ve esnek olmayan kserojel kaplamaların malzemenin yumuşaklığını düşürmesi beklenen bir durumdur [10,17].

Kütle değişimi sonuçları ile doğru orantılı olarak numunelerin sertlik oranlar1; D2>D1, D4>D3, D6>D5 şeklindedir. Bu da asidik ortamdaki sol ile hazırlanan kaplamanın bazik ortama göre rijitliğinin daha da fazla olduğu ve malzeme esnekliğini daha fazla düşürdüğü sonucunu göstermiştir.

Sol kompozisyonuna eklenen farklı yumuşatıcı maddeler ile bu rijitliği önleyebilmek mümkündür [10]. 


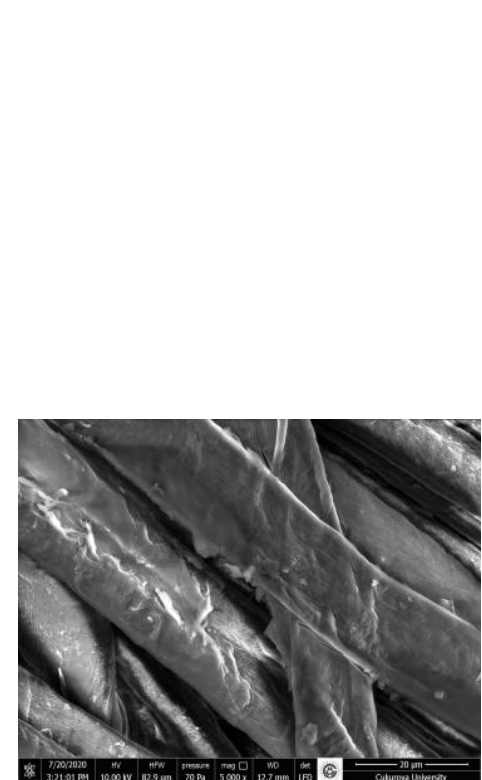

D1

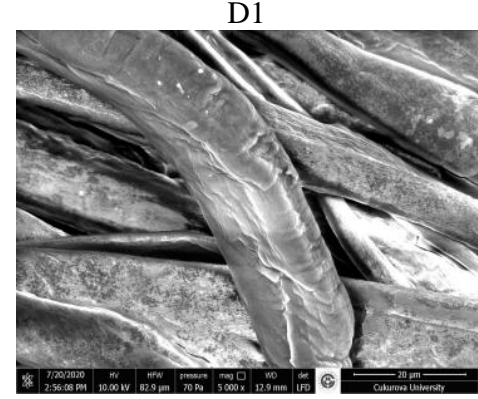

D4

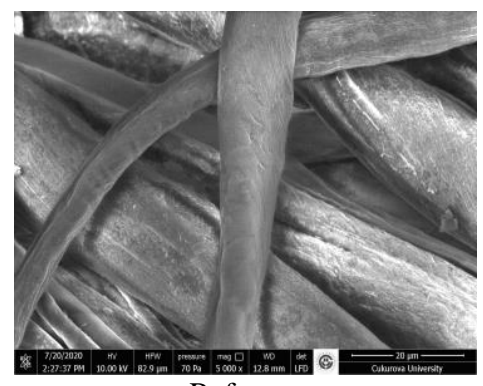

Referans

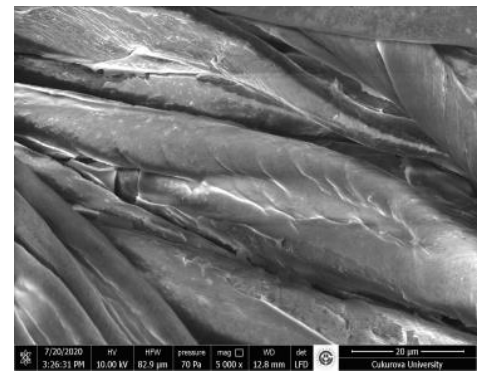

D2

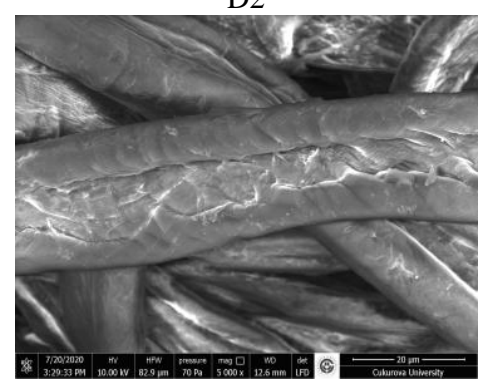

D5

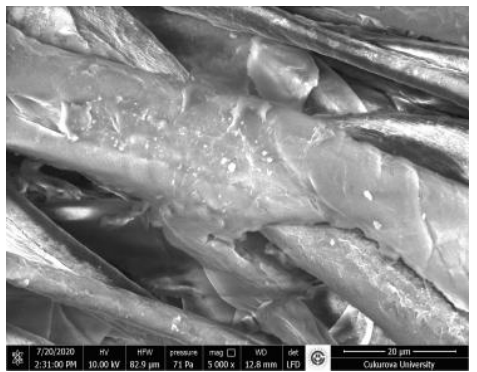

D3

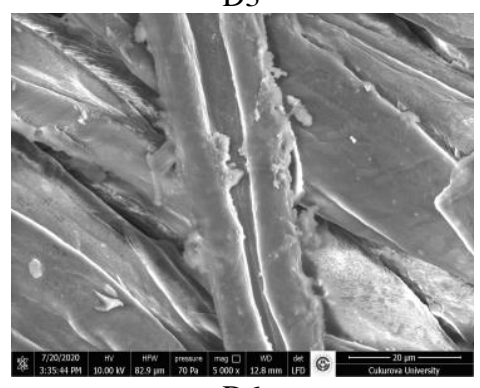

D6

Şekil 1. İşlem görmüş ve işlem görmemiş referans numunelerin SEM görüntüler

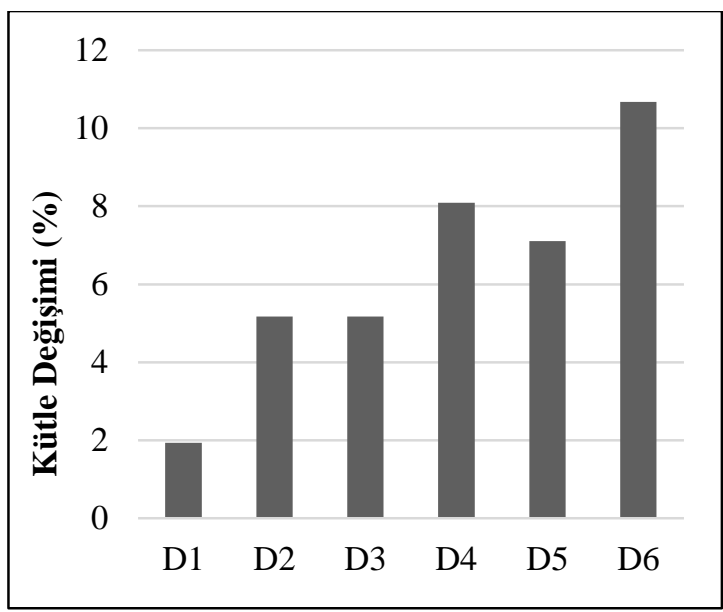

Şekil 2. Numunelerin işlem sonrası kütle değişimlerinin yüzde değerleri

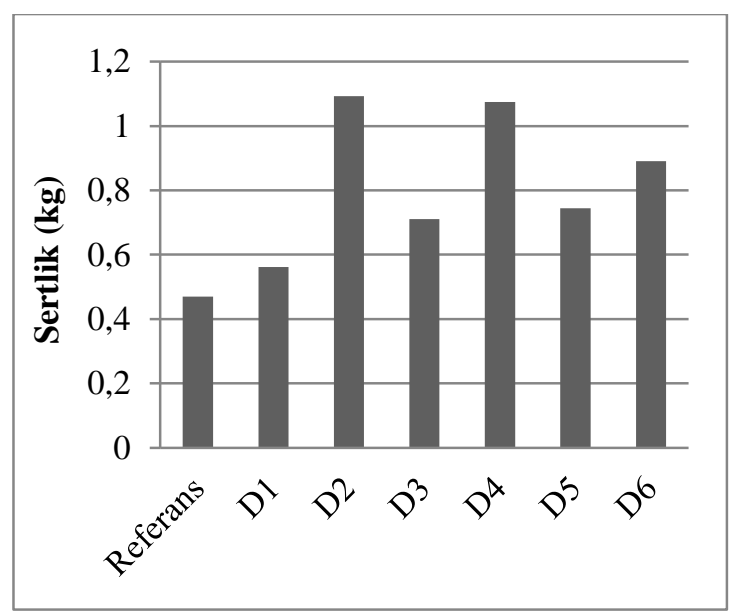

Şekil 3. Numunelerin sertlik değerleri 


\subsection{Hava Geçirgenlik Tayini}

Çalışmada hazırlanan denim numunelerin hava geçirgenlik sonuçları Şekil 4'de verilmiştir. Grafik incelendiğinde işlemler sonrası tüm numunelerin hava geçirgenlik değerlerinin artmış olduğu görülmektedir. Sol-jel tekniği ile hazırlanan kaplamalar kumaşın iplikler arasındaki boşlukları kapatmadığı için malzeme içinden geçebilecek hava akışının azalmaması beklenen bir durumdur.

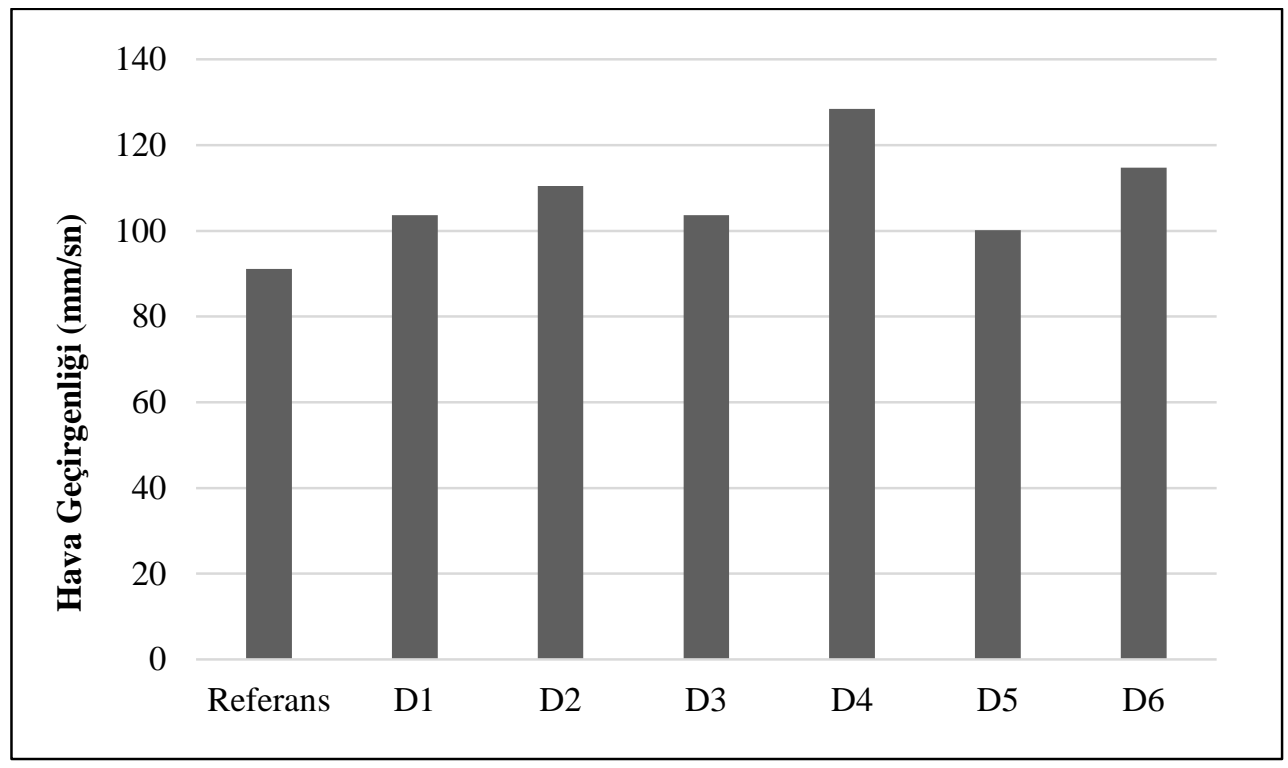

Şekil 4. Denim numunelerin hava geçirgenlik değerleri

Yine numunelerin işlem sonrası kütle değişimi (Şekil 2) sonuçları ile doğru orantılı olarak asidik ortamda hazırlanan solün bazik ortama göre numunelerin hava geçirgenliğini daha da arttırdığ ortaya çımışıtır. Sol bileşimindeki TEOS ve GPTS hacimsel oranının ise bu veriler üzerinde anlamlı bir etkisi yoktur.

Uygulanan işlemler sonrasında hava geçirgenliği artışııın işlem sonrası kumaş gözeneklerinin açılması ile açıklanabilmektedir. Sol içeriğindeki kat1 konsantrasyon arttıkça tekstil yüzeylerinin hava geçirgenliği artabilmektedir [10].

\subsection{Aşınma Dayanımı Tayini}

Şekil 5'deki grafikte tüm denim numunelerin 2500, 5000, 7500, 10000 ve 15000 devir aşındırma işlemi sonrası kütle kayıpları (\%) görülmektedir. Grafikteki verilere göre 15000 devir sonrasında D1 ve D3 numunelerinin aşıma dayanımları referans numuneye göre daha iyi çıkmıştır. Çapraz bağlayıcı içermeyen bazik ortamda hazırlanan sol ve TEOS:GPTS'nin 11:4 oranında bazik ortamda hazırlanan soller denim kumaşların aşınma dayanımını ortalama $\% 0,3$ arttırabilmiştir.

D4, D5 ve D6 numunelerinin ise kütle kayıpları referans numuneye göre daha fazla olup, 10000 devir aşındırma sonunda D5 numunelerinde yırtılma görülmüsştür. Sol kompozisyonunda çapraz bağlayıcı oranının en yüksek olduğu bu grupta numunelerin üzerindeki fazla miktarda kaplama, malzemenin dayanımını düşürmüştür. Özellikle aşınma sırasında kaplama malzemesinden kopan tozların/parçacıklarının bu aşındırıcı etkiyi daha da arttırdığı varsayıldığında D5 grubundaki numunelerde görülen yırtılmalar bu şekilde açıklanabilmektedir [18]. 
Tüm değerlendirmelere ek olarak bu sonuç; asidik solüsyonla işlem gören pamuklu denim numunelerin aşınma sırasında oluşan isıyla liflerinin zarar görüp kumaş yapısından uzaklaşmasıyla da açıklanabilmektedir.
Sonuç olarak pamuk içerikli denim numunelerin dayanımının bir miktar arttırılabilmesi açısından sol oluşumunda TEOS:GPTS hacimsel oranının 11:0 ya da 11:4 olması ve başlatıcı maddelerinin yüksek pH aralığında (alkali) katalize edilmiş hidrolizinin uygun olduğu tespit edilmiştir.

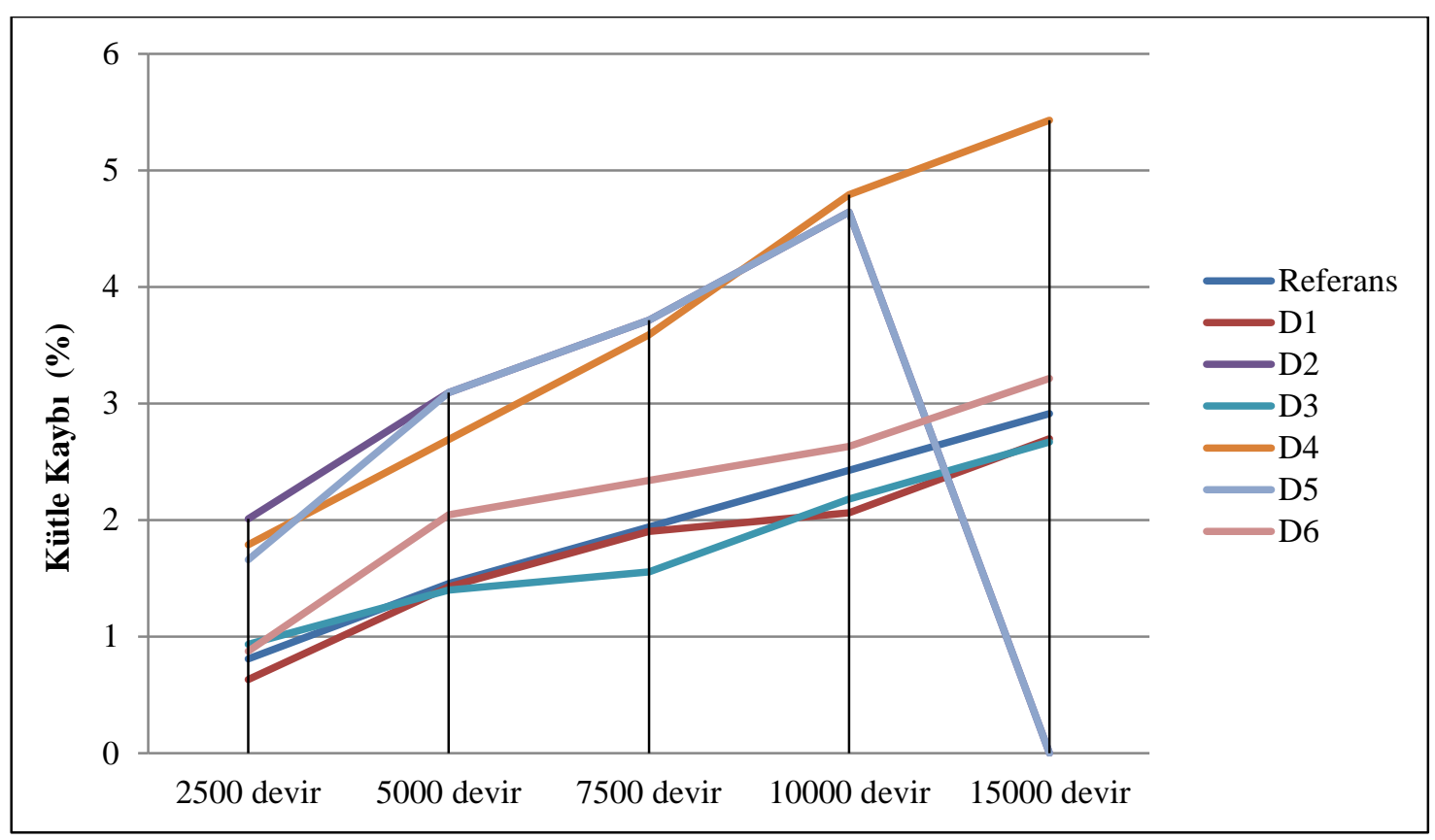

Şekil 5. Denim numunelerin aşındırma devri sonrası yüzde olarak kütle kayıpları

\section{SONUÇLAR}

Günlük hayatta yaygın olarak kullanılan giysilik kumaşlara yeni özellikler kazandırabilmek, boyama özellikleri ve renk haslıklarını geliştirebilmek, kullanım ömrünü uzatmak gibi amaçlar doğrultusunda fonksiyonel bitim işlemleri üzerinde yapılan çalışmalar giderek artmakta ve önem kazanmaktadır. Sol-jel tekniği de bir kaplama işlemi olarak tekstil alanında birçok araştırmada yer almaktadır.

$\mathrm{Bu}$ çalışmada da tekstil endüstrisinde en önemli ürünlerden birisi olan pamuk içerikli denim kumaşlara sol-jel tekniği ile kaplama uygulanarak bazı performans özelliklerinin ölçülüp, analiz edilmesi amaçlanmıştır. Başlatıcı madde olarak TEOS ve değișen hacim oranlarında GPTS kullanılmış ve bu şekilde asidik ve bazik ortamda ayrı ayrı soller elde edilmiştir.

SEM analizleri ile denim kumaşların lif yüzeyindeki kaplamalar doğrulanmıştır. Kütle değişim grafiklerine göre başlatıcı maddelerin asidik katalize edilmiş hidrolizi, bazik ortama göre numunelere daha fazla miktarda kaplama malzemesinin bağlanmasına yol açmıştır. Sol bileşiminde lif ve kaplama arasındaki adhezyon kuvvetinin artmasını sağlayan çapraz bağlayıcı madde oranı arttıkça numunelerin işlem sonrası kütlesindeki artış yükselmiştir.

İnorganik bir kaplama malzemesi olması nedeniyle tüm silika bazlı kaplama işlemleri, özellikle asidik ortamda hazırlanan solüsyonlar, denim numunelerde sertliğe neden olmuştur. Kaplama 
işlemi denim numunelerin gözeneklerinin açılmasına ve lif-iplik arasından geçen hava akışının artmasına sebep olmuştur. $\mathrm{Bu}$ sonuç özellikle sıcak havalarda tercih edilen denim kumaşlar için konfor özelliği açısından avantajlı bir durum oluşturmuştur.

Çalışmada denim numunelerde uygulanan işlemler arasında en iyi aşınma dayanımının sol kompozisyonunda TEOS:GPTS hacimsel oranının 11:0 ve 11:4 olduğunda ve bazik ortam ile elde edilebileceği görülmüştür. Bu oran 11:8 olduğunda ve asidik ortamda sol oluşumu gerçekleştiğinde; işlemlerin numunenin dayanımını düşürdüğü, aşınma sonrası bazı numunelerde yırtılmalar olduğu tespit edilmiştir.

Elde edilen sonuçlar doğrultusunda; sol-jel tekniği ile denim kumaşların kullanım ömrünün daha da arttırılabilmesi, yumuşak tuşe elde edilebilmesi ve farklı fonksiyonel özellikler kazandırılması açısından sol kompozisyonuna yumuşatıcı, lotus özellik kazandırabilen ve antibakteriyel madde gibi farklı katkı maddelerinin eklenmesi, aynı zamanda tekrarlı yıkamalar sonucunda kaplamanın kalıcılığı sağlanarak geleneksel denim bitim işlemlerine alternatif olarak bu tekniğin uygulanması sonraki çalışmalar için ön görülebilmektedir.

\section{TEŞEKKÜR}

Bu çalışma, FDK-2015-3368 no'lu proje kapsamında yapılmış olup Çukurova Üniversitesi Rektörlüğü BAP Koordinasyon Birimi tarafından desteklenmiştir. Ayrıca çalışmada denim kumaş teminini sağlayan BOSSA Ticaret ve Sanayi İşletmeleri firmasına teşekkür ederiz.

\section{KAYNAKLAR}

1. Shahbandeh, M., 2020. Global Denim MarketStatitcs\&Facts.https://www.statista.com/topics/ 5959/denim-market-worldwide/.

2. Annapoorani, S.G., 2017. Introduction to Denim: Sustainability in Denim, Duxford, UK: Woodhead Publishing, 765.

3. Güneşoğlu, S., 2015. The Statistical Investigation of the Effect of Hydrophilic
Polyurethane Coating on Various Properties of Denim Fabric, Tekstil ve Konfeksiyon, 25(3), 256-262.

4. Sabır, E.C., Doba Kadem, F., 2016. Comfort and Performance Properties of Raised and Laminated Denim Fabrics, Fibres and Textiles in Eastern Europe, 245(119), 88-94. http://dx.doi.org/10.5604/12303 666.1198064

5. Uğur, Ş.S., Sarışık, A.M., 2015. Deposition of Nanoparticle Multilayers to Improve Mechanical Properties of Denim Fabrics, The Journal of the Textile Institute, 106(7), 718-724.

6. Tölek, Ş., Kadem, F.D., 2016. Kaplamalı Denim Kumaşlarda Performans Özellikleri Üzerine Deneysel Bir Çalışma, Çukurova Üniversitesi Mühendislik-Mimarlık Fakültesi Dergisi, 31(2), 307-316.

7. Cirimina, R., Fidalgo, A., Palmisano, G., Ilharco, L.M., Pagliaro, M., 2016. Silica-based Sol-gel Coatings: A Critical Perspective from a Practical Viewpoint. In: Tiwari A, Galanis A, Soucek MD, eds. Biobased and Environmental Benign Coatings. Beverly: Scrivener Publishing LLC.

8. Brinker, C.J., Scherer, G., 1990. Sol-gel Science: The Physics and Chemistry of Sol-Gel Processing. San Diego, CA: Academic Press, 908.

9. Ismail, W.N.W., 2016. Sol-gel Technology for Innovative Fabric Finishing-A Review, Journal of Sol-Gel Science Technology, 78, 698-707.

10. Mahltig, B., Textor, T., 2008. Nanosols and Textiles, Singapore: World Scientific Publishing Co. Pte. Ltd., 33-53.

11. Mahltig, B., Haufe H., Böttcher, H., 2005 Functionalization of Textiles by Inorganic Solgel Coatings, Journal of Materials Chemistry, 15(41), 4385-4398.

12. Mahltig, B., Böttcher, H., Knittel, D., Schollmeyer, E., 2004. Light Fading and Wash Fastness of Dyed Nanosol-Coated Textiles, Textile Research Journal, 74(6), 521-527.

13. Sezgin Bozok, S., Ogulata, R.T., 2021. Effect of Silica Based Sols on the Optical Properties and Colour Fastness of Synthetic Indigo Dyed Denim Fabrics, Coloration Technology, 00, 1-8. https://doi.org/10.1111/cote.12521. 
14. ASTM D4032-94 Standard Test Method for Stiffness of Fabric by the Circular Bend Procedure, 2008.

15. TS EN ISO 9237, Tekstil Kumaşlarda Hava Geçirgenliğinin Tayini, Türk Standartları Enstitüsü, Ankara, 1995.

16. TS EN ISO ISO 12947-3, Martindale Metoduyla Kumaşların Aşınmaya Karşı Dayanımının Tayini-Bölüm 3: Kütle Kaybının Tayini. Türk Standartları Enstitüsü, Ankara, 1998.

17. Textor, T., 2009. Modification of Textile Surfaces Using the Sol-gel Technique. Surface Modification of Textiles. Cambridge, UK: Woodhead Publishing, 337.

18. Brzeziñski, S., Kowalczyk, D., Borak, B., Jasiorski, M., Tracz, A., 2012. Applying the Sol-Gel Method to the Deposition of Nanocoats on Textiles to Improve Their Abrasion Resistance. Journal of Applied Polymer Science, 125, 3058-3067. 
